\title{
Da Irretroatividade das Leis no Direito Romano.
}

\author{
R. Limongi França \\ Professor Adjunto de Direito Civil na Facul- \\ dade de Direito da Universidade de São Paulo.
}

\begin{abstract}
SUMARIO: I O PERÍODO PRÉ-CLASSICO. 1. A Legislação e a Doutrina antes de CÍCERO. 2. Das Verrinas ao Direito Clássico. II O PERIODO CLÁSSICO. 1. ULPIANO e PAULO. 2. As "Noities Aticas" de AULO GELIO e a correspondência de TRAJANO. 3. Ponderações sobre esta fase.
\end{abstract}

I. O PERIODO PRE-CLÁSSICO.

1. A Legislação e a Doutrina antes de Cícero. Sustentamos que a fase pré-científica do Direito Adquirido não começa com as Verrinas de Ć́cERo (106-43 a.C.), senão em uma quadra consideravelmente anterior.

E se a essa conclusão nos poderiam razoavelmente levar conjecturas em torno das leis republicanas dos séculos III e II a.C. e mesmo à face do elevado teor da argumentação do próprio discurso contra Verres, há certos dados concretos que consolidam o nosso modo de pensar.

Um deles é o referente à Lex Acilia Repetundarum, do ano 631 ou 632 de Roma, ou seja de 123 ou 122 a.C. Com efeito, o seu parágrafo 58, segundo a edição de BRUNs, diz o seguinte: "Quod ANTE H.L. ROGATAM consilio probabitur captum coactum ab latum avorsum consiliatumve esse, ea $(s)$ res omnis SIMPLI, ceteras res omnis, QUOD POST HANCE LEgEM ROGATAM consilio probabitur captum coactum ablatum avorsum consiliatumve esse, DUPLI etc" 1

1. BRUNS C.G., Fontes Iuris Romani Antiqui, 7.a ed., $\$ 909$. 
Com efeito, essa lei faz exata distinção entre os delitos praticados antes e depois da sua promulgação, cominando a pena simples para os primeiros e dupla para os últimos.

Discute-se sobre se, assim dispondo, esta lei não seria parcialmente retroativa, por isso que se ocupa também dos fatos anteriores à sua promulgação. TOMÁs MARKY esclarece que não, mostrando que a pena in simplum já se encontrava nas leis Calpurnia e Junia, até então em vigor. ${ }^{2}$

Mas ainda que retroativa fosse, fato de somenos se se the considerar o caráter excepcional, ${ }^{3}$ a redação do diploma em apreço revela um especial desenvolvimento da compreensão da matéria, suficiente para supor um tratamento doutrinário de certa envergadura.

Não ficamos aí, entretanto.

Essas lucubrações de caráter pré-científico podem ser recusadas até aqueles que, no dizer de POMPôNIO, fundaverunt jus civile 4 a saber Publius Mucius Scaevola, Brutus e Manrlius, dos quais o primeiro foi cônsul em 133 a.C. e o último em 149 a.C. ${ }^{5}$.

A discussão a respeito da matéria por parte destes que são os grandes precursores da Ciência Jurídica Romana, é narrada por Aulo Gelio, que por sua vez se baseou em informações de Quintus Mucrus ScAEvola (Cônsul em 95 a.C.), filho de Publius Mucius. Girou em tôrno da Lei Atínia, de 555 a 622 de Roma, com caráter puramente teórico, estando a notícia das suas considerações vazada nestes têrmos: "As palavras da velha Lei Atínia são estas: Quod subreprum erit eius rei aeterna auctoritas esto. (Se uma coisa foi roubada, a respectiva ação será eterna). Quem descreria de que, com tais palavras, a lei se refere apenas aos casos futuros? Mas, Q. Scaevola afirma que seu pai, BRUTo e MANílIo, varões doutíssimos, tiveram dúvida sobre se tal lei abrangia ape-

2. TOMÁS MARKY, Apputi sul Problema della Retroattività delle Norme Giuridice nel Diritto Romano, Milão, 1948, p. 246-147. Sobre a matéria, v. ainda o ensaio de GERARDO BROGGINI, sucessor de AFFOLTER em Heidelberg - La Retroattività della Legge nella Prospettiva Romanistica, in "Studia et Documenta Historiae et Juris", XXXII, p. 1-62, Roma, 1966.

3. CONTARDO FERRINI, Manuale di Pandete, p. 40, 4.a ed., Milão 1953. Mostra que o ius quaesitum, excepcionalmente pode ser atingido, pelas memas razões da desapropriação por utilidade pública.

4. Digesto, 1, 2, 39: "Post hos fuerunt Publius Mucius, et Brutus, et Manilius: qui fundaverunt jus civile".

5. TOMÁS MARKY, op. cit., p. 247, nota 2. 
nas os roubos futuros ou também os anteriores, porque estas palavras subreptum erit - pareciam corresponder tanto ao tempo pretérito como futuro" 6 .

A seguir, Aulo Gélio se refere às considerações sobre o assunto levadas a efeito por Públio Nigídio, no livro Commentariorum Grammaticorum, cujo interesse é menor não só devido ao cunho filológico do trabalho deste, como ainda pelo fato de ter vivido de 90 a 45 a.C. portanto,já ao tempo de Cícero 7

Mas, no que concerne aos estudos dos chamados Veteres (PuBLIUs Mucius, Brutus e Manilius), é de grande importância considerar que daí se depreende que, já em meados do século II a.C., portanto cerca de três quartos de século antes das Verrinas, a idéia da irretroatividade já estava grandemente arraigada no espírito jurídico dos romanos. Note-se ainda um fato particularmente relevante: CícERo, em sua juventude, fôrra discípulo em Direito do jurisconsulto Quinto Mucius ScaEvola, filho de Publius Mucius ${ }^{8}$.

2. Das Verrinas ao Direito Clássico. Estas considerações parecem explicar o alcance da célebre apóstrofe da Segunda Oração contra Verres, cuja tradução é a seguinte: "PubliUs ANNIUs fizera um testamento, pelo direito, pelas leis e pela autoridade dos jurisconsultos, não ímprobo nem desumano; $e$, ainda que tivesse feito o contrário, não teria cabimento que, depois da sua morte, se estabelecesse uma nova regra sobre o seu testamento. Parece-te que a Lei Vocônia te satisfaz? Então, fôra bem que tivesses imitado a $Q$. VoconIus, o qual, com a sua lei,

6. AULUS GELIUS, Noctes Atticae, 17, 7: "Legis veteris Atiniae verba sunt. QUOD SUBREPTUM ERIT; EIUS REI AETERNA AUCTORITAS ESTO. Quis aluid putet in hisce verbis, quam de tempore tantum, futuro legem loqui? Sed Q. Scaevola, patrem suun, et Brutum, et Manilium, viros apprime doctos, quaesisse, ait, dubitasseque, utrumne in post-facta modo furta lex valeret, an etiam in ante-facta? quoniam QUOD SUBREPTUM ERIT utrumque tempore videretur ostendere, tam praeteritum quam futurum" A edição que seguimos é a de NISARD, Paris, 1842. Não the acompanhamos, porém, a tradução a nosso ver demasiada livre e menos precisa. Desta discussão dos veteres há um resquício no Digesto, 50, 16 , 123, De Verborum Significatione, fragmento de POMPÔNIO, Ad. Q. Mucium, L. 26 (-cf. TOMÁS MARKY).

7. V. MASERA, JOÃO, Compêndio de História da Literatura Latina, in RAVIZZA, Gramática Latina, 6.a ed. s/., p. 485. Por sua vez AULO GÉLIO viveu de 115 a 165 a.C. (V. p. 614).

8. MASERA, op. cit., p. 479. 
não privou do direito à herança nem as virgens nem as mulheres; e sancionou posteriormente que ninguém fizesse herdeira a uma virgem ou mulher depois de ter sido recenseado por aqueles censores (A. PostuMIUs e Q. Fulvius, v $\S \mathrm{XLI})$. Na Lei Vocônia não está escrito - FEZ, FIZESSE; nem por meio de alguma lei se abrange o tempo passado, a não ser com relação a fatos tais que, por sua natureza criminosa e nefasta, devem ser reprimidos, ainda que lei não houvesse. Mesmo assim, com relação a esses fatos, vemos que muitos deles não são reprovados em juízo, porque praticados anteriormente. A Lei Cornélia sobre os testamentos, a lei da moeda, e outras que tais; ${ }^{9} \mathrm{em}$ não trazendo nenhum direito novo, determinaram que toda ação má tivesse a respectiva questão deferida ao povo a partir de um determinado tempo. Pois não é verdadeiro que, em matéria de direito civil, nada do que anteriormente se fêz se pode regular pelo direito novo? Trazei-me a Lei Atínia, a Fúria, aquela que citei, a Vocônia, e outras mais de direito civil: aí encontrareis, em todas elas, que as suas regras foram estatutidas para que o povo as aplicasse a fatos posteriores. Mesmo aqueles que atribuem grande valor ao edito do pretor, são os primeiros a chamarem-no lei ânua. E no entanto pretendes tu que o edito valha mais que a lei. Se o fim da vigência do edito se dá nas calendas de janeiro, como nas mesmas calendas de janeiro pode deixar de ter reinício um novo edito? $E$ se, de um lado, a ninguém é permitido fazer com que o edito ultrapasse o ano respectivo, como, do outro, se pode admitir que a sua eficácia regrida ao ano do pretor antecedente 10 ?

9. V. JULII PAULI SENTENTIARUM, IV, 7; V. 23; V. 25. A lei Cornélia, além de outras matérias, dispunha sobre os testamentos, ed. de DAUBANTON, in Le Trésor de l'Ancienne Jurisprudence Romaine, p. 228, 265, 267, Metz, 1811.

10. "Jure legibus, auctoritate omnium, que consulebantur, testamentum $P$. Annius fecerat, nom improbum non inhumanum: quod si ita fecisset, tamen post illius mortem nihil de testamento illius novi juris constitui oporteret. Voconia, lex te videlicet delectabat? imitatus esses ipsum illum Q. Voconium, qui lege sua hereditatem ademit nulli neque virgini, neque mulieri; saniat in posterum, qui post eos censores census esset, ne quis heredem virginum, neque mulierem faceret. In lege Voconia non est, FECIT, FECERIT: neque in ulla prasteritum tempus reprehenditur, nisi ejus rei, quae sua sponte scelerata ac nefaria est, ut, etiamsi lex non esset, magnopene vitanda fuerit. Atque in his rebus multa videmus ita sancta esse legibus, ut ante facta in judicium non vocentur. Cornelia, testamentaria, nummaria, ceterae complures: in quibus non jus aliquod novum populo constituitur, sed sancitur ut, quod semper malum facinus fuerit, ejus quaestio ad populum pertineat, ex certo tempore, is jure 
Como se vê, neste belíssimo texto do discípulo de Quintus MUcIUS SCAEvola, a despeito do seu argumento último - onde nos parece sofisma, pois da não ultra-atividade do edito pretende deduzir a sua irretroatividade, atributos, a nosso ver, de natureza diversa - inegável que se encontra bem nítido o princípio geral da irretroatividade da norma jurídica, bem assim o germe da noção do próprio Direito Adquirido ${ }^{11}$ Com efeito, o grande tribuno já defende a impossibilidade de uma lei nova modificar o rumo da herança testamentária, estando aberta a sucessão: quod si ita fecisset, tamen post illius mortem nihil de testamento illius novi juris constitui oporteret 12

O amadurecimento desta orientação jurídica ressalta ainda de outros elementos que encontramos na época, tanto no testemunho dos autores, como Publius Nigidius, que além de gramático fora também pretor em 58 a.C. ${ }^{13}$, como no texto dos diplomas legais, conforme se vê na Lei Falcídia, de 40 a.C., cujo texto, largamente transcrito e comentado no Digesto, ao longo de noventa e três fragmentos, se refere a qui eorum post hanc legem rogatam testamentum facere volet ${ }^{14}$.

vero civili si quis novi instituit, is non omnia, quae ante acta sunt, rata esse patietur? Cur mihi leges Atiniam, Furiam (no texto está com s), ipsam, qui, dixi, Voconiam, omnes praeterea de jure civili; hoc reperies in omnibus statuit jus, quo post eam legem populus utatur. Qui plurinum tribuunt edicto, praetoris edictum legem annum dicunt esse. Tu edicto plus complecteris, quam lege. Si finem edicto praetoris affierunt Kalendae januarii; cur non initium quoque edicti nascitur a Kalendis januarii? an in eun annum progredi nemo poterit edicto, que praetor aius futurus est; in illum, quo illius praetor fuit, regredietur? CICERO,

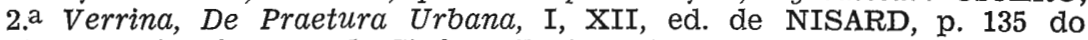
Tomo II das Oeuvres de Cicéron, Paris, 1850.

Bem sabemos que a praxe científica é não traduzir o latim. Não obstante, permitimo-nos fazê-lo com o intúito menos de elucidar o conteúdo do texto, do que de lhe apresentar a nossa pessoal interpretação. Uma detida e valiosa análise desse texto se encontra em BROGGINI, G., La retroatività della legge nella prospettiva romanística, in Studia et Documenta Storiae et Juris, vol. XXXII, p. 34 e seguintes, n.o 6.

11. CICERO tratou ainda incidentemente da matéria no De Legibus, II, IV in fine; III, XIX, in fine, ed., de CHARLES APPHUN, Ciceron, de la Republique, des Lois, p. 283 e 377, Paris, 1954.

12. V. SAVIGNY, Sistema del Diritto Romano Attuale, vol. VIII, p. 394, nota b-1, ed. de Scialoja, Turim, 1898. Não nos esqueçamos de que, em certos casos, a transmissão de herança dependia da aditio hereditatis (v. VANDICK LONDRES DA NÓBREGA, Sistema do Direito Privado Romano, p. 588, 3. ${ }^{\mathrm{a}}$ ed., Rio, 1961).

13. AULUS GELLIUS, Noctes Atticae, loc. cit.; MASERA, op. cit., p. 485.

14. Digesto, 35, II, 1, pr., fragmento de PAULO; BRUNS, op. cit., p. 110. 


\section{O PERIOODO CLÁSSICO}

1. Ulpiano e Paulo. E curioso notar que exatamente o período áureo da Ciência Jurídica Romana, à face dos dados de que dispomos hoje em dia, tenha sido o mais pobre no que concerne ao objeto deste trabalho.

Romanistas celebérrimos, como SAVIGNY e FERRINI, respeitáveis especialistas do Direito Transitório, do porte de GABBA, Roubier e GaETANO PACE, e mesmo autores do monografias especializadas sobre a matéria no Dineito Romano, entre eles REINALdo Porchat e ToMás Marky 15, expressa ou implicitamente indicam que, em todo o Digesto, inexiste qualquer texto rigorosamente destinado à regulamentação do assunto. Segundo alguns autores, isto teria sido em razão da "índole óbvia" (do Princípio da Irretroatividade das Leis) e da reflexão de que bem pouco fora de se acrescentar à formulação de CícERo e às razões que adotara para sua sustentação" 16

Dois textos, entretanto, tem sido objeto de particular atenção: um, de Ulpiano, 4. 38, 17, 1, 12; o outro de Paulo, D. 50, 16, 229-230 17

O primeiro assim reza: "Estas palavras do Senatusconsulto - Devem permanecer válidas as coisas julgadas, transacionadas ou concluidas — têm o sentido seguinte: coisa julgada, aquilo que é julgado por juiz competiente; transacionada, aquela que se transacionou de boa-fé; concluída, a situação consolidada pelo consentimento ou pelo longo silêncio" 18. O segundo, que se encontra no título De Verborum Significatione, está vazado nestes termos: "Devemos entender por negócios transacionados ou concluídos não só aqueles a respeito dos quais houve con-

15. SAVIGNY, Sistema, VIII, $\S \S 385-387$; FERRINI, Manuale, p. 39-42; GABBA, Teoria della Retroattività delle Leggi, I, p. 46-50, 3.a ed., 1891; PAUL ROUBIER, Les Conflits des Lois dans le Temps, I, p. 65-66, 1.a ed., 1929; GAETANO PACE, op. cit., p. 36; REINALDO PORCHAT, Curso Elementar de Direito Romano, p. 496-503, São Paulo, 1907; REINALDO PORCHAT, De Retroatividade das Leis Civis, p. 71-80, São Paulo, 1909; TOMAS MARKY, op. cit., p. 259-263.

16. GAETANO PACE, Il Diritto Transitorio, Milão, 1944,p 36.

17 V. ROUBIER, AFFOLTER, GAETANO PACE, MARKY.

18. ULPIANO, D. 38, 17, 1, 12: "Quod ait senatus: Quae judicata, transacta finitave sunt, rata maneant: ita intelligendum est, ut judicata accipere debeamus, $a b$ eo cui judicandi jus fruit; transacta, scilicet bona fide, ut valeat transactio: finita, vel consiensu, vel longo silentio sopita". 
trovérsia, senão também aqueles que sem controvérsia se entabularam" - Assim se consideram a coisa julgada, a que se compôs por transação e a que se consolidou em virtude de um longo silêncio" 19 .

As considerações de UlPiano e as do parágrafo 230, de PAUlo, foram feitas à guisa do Senatusconsulto OrficIANo, e dos seus termos deduziu TOMás MARKY que esse diploma era parcialmente retroativo, uma vez que só respeitava as causae finitae ${ }^{20}$. Por outro lado, fala na inauguração de um sistema novo, em relação ao período anterior, pois enquanto, durante a República, se usavam as expressões post hanc legem ante hanc legem, nesta fase se utilizam os vocabulos post facta - ante facta.

Mais afoitas são as conclusões de Gaetano PaCE. Diz ele que "O conceito esclarecido pelos dois jurisconsultos é aquele de causae finitae, isto é, de relação jurídica exaurida: uma relação sobre a qual as novas leis, mesmo se retroativas, salvo disposição expressa, não atingirão mas respeitarão". E acrescenta: "Depois da elaboração de tal princípio, o sistema jurídico transitório dos romanos (como se diria hoje) vem a ser constituído: de uma regra geral (a irretroatividade das leis civis); de exceções (retroatividade), para os casos expressadamente previstos; enfim, de uma regra sobre a exceção (o limite das causae finitae para as leis retroativas) 21

Roubier, cujas lições serviram de base a GAETANo PACE, traz ainda um complemento para tais idéias: segundo este sistema a nova lei se aplicava às causae pendentes ${ }^{22}$

De nossa parte, no que concerne a este período, pedimos vênia para considerar o seguinte.

Inicialmente, parece-nos autorizado assinalar a efetiva pobreza dos clássicos no que se relaciona com o Direito Intertemporal. Com efeito, não é crível que, se o material existente fosse mais abundante, TriboNIANO e os seus auxiliares não o tivessem aproveitado melhor na elaboração do Digesto, onde vários títulos tem ligação direta com o assunto

19. PAULO, D. 50, 16, 229: "Transacta finitave intelligere debemus, non solum quibus controversia fuit, sed etiam quae sine controversia sint possessa" - $§ 230$ "Ut sunt judicio terminata, transactione composita, longioris temporis silentio finita".

20. TOMÁS MARKY, op. cit., p. 260.

21. GAETANO PACE, op. cit., p. 37.

22. ROUBIER, Les Conflits des Lois dans le Temps, I, pág. 67. 
23 Máxime diante da circunstância de, pelos dados de que dispomos, ter sido JUSTINIANo um imperador que de modo muito especial voltou as suas atenções para o problema da irretroatividade das leis.

Por outro lado, entre as obras do tempo que, de modo mais ou menos completo chegaram até nós, a saber, as Institutas de GAIO ${ }^{24}$, as Regras de Ulpiano ${ }^{25}$ e as Sentenças de Paulo ${ }^{26}$ a despeito da constante incidência de matéria correlata, não encontramos consideração alguma de efetivo interesse.

2. As Noites Áticas de Aulo GéLIo e a correspondência de TRAJANO. Não obstante, contamos com elementos que nos permitem concluir que o senso do Princípio da Irretroatividado das Leis era, a essa época, bastante arraigado no espírito romano, graças à elaboração dos Veteres e dos mestres, como CícERo, imediatamente anteriores. Aí está, em Auno Gélio, que viveu em pleno período clássico (de 115 a 165 d.C.) a digressão sobre a Lei Atínia, a crítica indireta a Públıo Múcıo e seus coevos e, sobretudo, a expressão de um ponto-de-vista não apenas seu, se não geral: Quis aliud putet in hisce verbis, quam de tempore tantum futuro legem loqui? Em português, literalmente: "Quem (que pessoa) outra coisa entenderá nestas palavras, senão que a lei (Atínia) fala apenas do tempo futuro? 27

O mesmo se confirma com a correspondência epistolar entre PlíNio, o Moço, e o Imperador Trajano, em meio à qual, à guisa da Lei Pompéia, diz este último o seguinte: “ nada inovaremos com relação ao passado, de modo que permaneçam como estão os cidadãos constituídos (senadores) quaisquer que sejam as suas cidades de origem, ainda que isto seja contra a lei; pois a Lei Pompéia só se observará para o futuro: se, com efeito, quiséssemos dispor para o passado, tal implicaria necessàriamente muitas perturbações" 28

23. D. 11 De Justitia et Jure; D. 1, 3, De Legibus, Senatusque Consultis, 'et Longa Consuetudine; D. 1, 4, De Constitutionibus-Principum.

24. GAIO, Institutas, in Manual de Direito Romano, de CORREIA, SCIASCIA, e A. A. CASTRO CORREIA, vol. II, 2. ${ }^{a}$ ed., 1955.

25. ULPIANO, Regras, ed. de GAETANO SCIASCIA, 1952.

26. PAULO, Julii Paulii Sententiarum Receptarum ad Lilium in "Le Trésor de l'Anciènne Jurisprudence Romaine", Metz, 1811.

27. AULO GÉLIO, op. et loc., cits.

28. .. ut ex praeterito nihil novaremus, sed manerent, quamvis contra legem, adsciti quarumcunque civitarum cives, in futurum autem lex Pompeia observaretur: cujus vim si retro quoque velimus custodire, 
3. Ponderações sobre esta fase. Isto posto, se os clássicos não tiveram elaboração própria, relacionada com o Direito Transitório, e se tão clara era a sua idéia do mesmo, a primeira conclusão a que se chega é a de que o sistema que adotavam era o do período anterior. Ora, no período anterior avulta a figura de CíCERo em cujas Verrinas vemos a sustentação da irretroatividade não só com relação às causae finitae, o que aí vai implícito, como ainda no que, de certo modo, concerne às causae pendentes, pois a sua invectiva é concernente aos efeitos do testamento de Publius Annius 29

Por outro lado, no conceito clássico de negotia finita (a expressão nos parece mais própria causa finita, pois UlPiaNo usa o plural neutro - rata maneant - e não o feminino singular) não nos esqueçamos de que se inserem aqueles concluídos vel consensu, isto é, pelo consentimento, mesmo sine controversia, portanto, os negócios jurídicos comuns, independentemente de intervenção judicial. Ora, parece não haver elementos que desautorizem a tese da validade dos seus efeitos à face da lei nova.

Quanto ao uso sistemático das expressões - ante facta, post facta - observamos que não constitui uma constante. Em mais de um lugar das Sentenças de PAUlo a formula utilizada foi outra, a saber, antea nunc e antea hodie ${ }^{30}$.

Finalmente, é de se assinalar a lição de Mattos Peixoto, segundo a qual, de vários textos do Digesto, se deduz que, em matéria penal, a regra vigente entre os clássicos era a da proporcionalidade da peno ao crime, independentemente de haver ou não lei anterior ${ }^{31}$ Ora, em suma, esta fora igualmente a orientação marcada por CícERo, nas Verrinas, onde assevera que certos crimes se devem punir mesmo que nenhuma lei os tenha previamente definido, nisi eius rei, quae sua sponte scelerata ac nefaria est ut, etiamsi lex non esset, magnopere vitanda fuerit.

multa necesse est perturbari". TRAJANUS PLINIO C. CXVI, infine. "Ci Plinii Caecilii Secundi EPISTOLAE ıt Panegyricus" ed. de LALLENAND, Paris, 1769 , p. 349-350. PLÍNIO, o Môço, sobrinho materno de PLINIO, o velho, nasceu em Como, em 62 d.C. (MASERA, p.5 10).

29. Mais tarde, JUSTINIANO, viria a estabelecer claramente que se respeitassem os testamentos, ainda que a nova lei se publicasse em vida do testador.

30. PAULO, Sentenças, V. 24, Ad legem Pompeiam; V. 29 Ad legem Juliam.

31. MATTOS PEIXOTO, Curso de Direito Romano, p. 235-240, 4. ${ }^{\text {a }}$ ed., 1960; Cf. CONTARDO FERRINI, Diritto Penale Romano, cap. II, p. 32, ed. 1899. 
III. O PERIODO POS-CLASSICO.

1. O primarismo Jurídico deste período. O Período Pós Clássico, a despeito da gigantesca obra restauradora de Diocleciano ${ }^{32}$ e da consolidação da Monarquia Absoluta, ao longo de quase três séculos, foi, até Justiniano (527-565), de uma grande aridez para o Direito.

Não obstante o legado dos Clássicos e a multiplicidade das escolas jurídicas, fundadas a partir do século III, entre as quais atingiram grande fama as de Beirute e de Constantinopla, além das menos famosas, de Alexandria, Antióquia e Cesarea (33), o início da revivescência do Direito só se dará a partir de Teodósio II e Valentiniano III (408-450 e 425-455). Mesmo assim, é sabido que o plano de elaboração juríidica de Teodósio II, que resultou no Codex Theodosianus (438, com vigência no Oriente, a partir de $1 .^{\circ}$ de janeiro de 439 ), teve de ser restringido em suas ambições iniciais, "sem dúvida alguma em razão da insuficiente preparação doutrinal dos comissionados" 34 .

Duas parecem ter sido, ao lado de muitas outras, as razões fundamentais desse verdadeiro primarismo jurídico da quadra em aprêço: de um lado, a Anarquia Militar que grassou no Império durante quase meio século; ${ }^{35}$ do outro, a completa modificação dos órgãos produtores do Direito, reduzidos praticamente ao poder absoluto do monarca, Dominus et Deus 36

32. THEODORO MOMMSEN, Compêndio del Derecho Publico Romano, pág. 478, B. Aires, 1942: “... disfrutó el Estado romano de una primavera outoña1, que habiendo asomado ya en tiempo de AURELIANO, restauró completamente el Estado durante los veinteun años de gobierno del imperador DIOCLESIANO (284-305)" ..

33. ARANGIO-RUIZ, Historia del Derecho Romano, trad. da 2. ed. italiana, pelo Prof. F. P. IVAÑEZ, p. 434-435, Madri, 1943. V. sobretudo, a monografia do preclaríssimo mestre, Prof. ALFREDO BUZAID, A Escola de Direito de Beirute, São Paulo, 1951.

34. A comissão inicialmente nomeada, em 429 (C. Th. 1, 1, 5), era composta de sete funcionários e um professor de Direito. Diante do seu fracasso, nova comissão se nomeou em 435, com incumbências menos amplas C. Th. $1,1,6)$. V. ARANGIO-RUIZ, op. cit., p.4 30-431.

35. Sobre as consequências econômicas-sociais da Anarquia Militar, de 235, Morte de Al. Severo, a 284, V. M. ROSTOVTZEFF, História Social $y$ Econômica del Império Romano, T. II, p. 327 e seguintes, Madri, 1937.

36. MOMMSEN, Derecho Público Romano, p. 487; ARANGIO-RUIZ, História, p. 426; VANDICK LONDRES DA NÓBREGA, op. cit., p. 99. 
No que tange ao objeto específico deste trabalho, a insipiência não podia ser maior, pois, como vimos, não teria havido sequer uma elaboração própria dos jurisconsultos do período anterior.

Não nos parece, entretanto, no que tange à matéria, e quiçá em quanto se relaciona com o Direito em geral, que se possa abarcar todo esse período dentro de uma única perspectiva. Duas épocas aí nos parecem oferecer características particulares: uma que vai até a última década do século IV, quando do reinado de Teodósio I; e outra que, a partir dessa quadra, se estende até a subida de Justiniano ${ }^{37}$.

O fato marcante, que serve como linha divisória de ambas essas fases é a chamada Primeira Regra Teodosiana, do ano de 393, segundo a qual - "Todas as normas não fazem calúnia aos fatos passados, mas regulam apenas os futuros" - omnia constituta non praeteritis calunian aciunt sed futuris regulam ponant ${ }^{38}$. Embora tivesse sido endereçada a uma finalidade imediata, esta constituição teve o mérito de dar forma a um princípio geral que já vinha da República, a ponto de aparecer no livro I do Código do Theodósio II. Além disso, ao que nos parece, foi a grande fonte inspiradora da Segunda Regra Teodosiana, ou Regra Teodosiana por antonomásia. Tal regra não só caracteriza o Direito Transitório da outra época do período Pós-Clássico, mas ainda veio a constituir o princípio fundamental que dominou o sistema justinianeu nesta matéria.

2. A Época Pré-Teodosiana. Os autores constantemente dão realce ao fato de existirem, datadas da Época Pré-Teodosiana, muitas leis retroativas, ao lado de outras irretroativas 39

Parece-nos lícito asseverar, entretanto, que, mesmo à falta de uma disposição geral desse tempo ${ }^{40}$, não se pode negar a irretroatividade como regra. O teor incisivo da Primeira Regra Teodosiana, já de si mostra como se tratava de um princípio profundamente arraigado no espírito ju-

37. TEODÓSIO I, imperou de 392 a 395 e Justiniano foi elevado em 527, para governar até à morte, em 565 .

38. C. Th. 1, 1, 3. A finalidade imediata desta constituição foi reparar certas injustiças de TACIANO, prefeito do pretório.

39. V. GABBA, op. cit., I, 47; ROUBIER, I, 69; TOMÁS MARKY, 284.

40. O Código Gregoriano e o Hermogeniano, que consultamos pela edição de DOUBANTON, Metz, 1811, e que datam do tempo de DIOCLECIANO (291-292 e 293-294, respectivamente) não trazem disposições de natureza intertemporal. 
rídico de então. Por sua vez a Segunda Regra Teodosiana, de que nos ocuparemos mais adiante, usando da expressão certum est, confirma esta nossa afirmativa.

Mas, sobretudo, em algumas constituições, como a do C.Th. 4, 12, 1, ad Sc Claudianum, do ano 314, mais tarde secundada pela do C. Th. $12,3,2$, de prediis et mancipiis, de 4,23 , encontramos as expressões de praeterito custodire OPORTER, praeteritas vero emptiones infirmari OPORTEAT - que evidenciam, através do verbo oportere o caráter excepcional da retroatividade. O emprego desse vocábulo que, a nosso ver, aí aparece como verdadeira exposição de motivos, avulta em significado quando se considera o poder dos imperadores de então ${ }^{41}$

Parece-nos relevante, entretanto, a circunstância de as leis retroativas da época se referirem genericamente ao praeteritum, sem qualquer discriminação de limites ${ }^{42}$. Embora linguajar semelhante tenha sido usado também no Período Clássico ${ }^{43}$, e, ainda que, na Epoca Pré-Teodosina, daí pudessem estar mplicitamente excluídos os negotia ou facta finita 44, o certo é que um tão constante e limitado hábito constitui o indício, se não a prova, de que, efetivamente, a análise jurídica do tempo padecia de meios técnicos primários de tal forma que, com relação ao Direito Intertemporal, se pode falar em verdadeiro retrocesso científico, à face dos Clássicos e dos próprios juristas da República.

3. A Época Teodosiana. A Época Teodosiana, entretanto, irá modificar esse estado de coisas e preparar a revivescência justinianéia, não só no Direito em geral, mas outrossim no que particularmente concerne ao problema da irretroatividade das leis.

A) Teodósio I e Anastácio. Nesta quadra, conquanto dominada pelo vulto de Teodósio II, em virtude do seu célebre Codex, se devem ressaltar ainda duas figuras proeminentes: a do seu antecessor TeoDósIo I e a de ANASTÁcio, que reinou de 491 a 518, portanto, até nove anos antes de JUSTINIANO.

41. Theodosiani libri, XVI, vol. I-1, p. 189, ed de MOMMSEN-KRUEGER, Berlim, 1954; Cf. p. 711.

42. V. TOMASS MARKY, op. cit., p. 266.

43. PLINIO, Epistolae, CXVI: “.. ut ex praeterito nihil novanemus".

44. Mais tarde, como se verá adiante, já na Época Teodosiana, uma constituição de ANASTÁCIO (491-518) se refere expressamente a definitivis sententiis; Cód. 4, 29, 21. 
Teodósio I, em virtude da Primeira Regra Teodosiana, de que já falamos. E ANASTÁcio, devido ao alto significado de várias constituições suas, particularmente, de duas, a saber, a do Cod. 4, 29, 21 e a da mesma compilação 10,31 , 65. A primeira, numa disposição final de caráter transitório, com certa riqueza técnica, exclui os "contratos passados" (praeteritos contractus) e os "negócios e controvérsias concluídos por transação, por sentença definitiva ou por outro modo legítimo (pro netiis et controversiis necdum transactionibus, vel definitivis sententiis, seu alio legitimo modo sopitis). Na outra, à semelhança de TEoDósıo I, utizando-se da expressão - calumnias excitare — reconhece não só a irretroatividade como princípio geral, como ainda o caráter odioso, que, em princípio, a retroação encerra 45

B) A Segunda Regra Teodosiana. De incomparável valor, entretanto, para o progresso científico do Direito Transitório é a Segunda Regra Teodosiana, cujo teor é o seguinte: "Leges et constitutiones futuris certum est dare formam negotiis, non ad facta praeterita revacari, nisi nominativa et de praeterito tempore, et adhuc, pendentibus negotiis cautum sit. A tradução que proporíamos é esta: "É norma assentada (certum est) a de que as leis e constituições dão forma aos negócios futuros (futuris negotiis) e de que não atingem fatos passados (facta praeterila), a não ser que tenham feito referência expressa (nominatim cautum sit), quer ao passado (praeterito tempore), quer aos negócios pendentes (pendentibus negotiis)"

Esta constituição, a Regra Teodosiana, por antonomásia, é uma novela de TEodósıo II, pois, datando de abril de 440, não se encontra no seu Codex, cuja publicação se deu dois anos antes. O lugar onde se encontra é o Código de Justiniano, promulgado em 530 e depois, em reedição, em 534, no título De legibus et constitutionibus Principum et edictis ${ }^{46}$

C) Ponderações sobre a Segunda Regra Teodosiana. Vários aspectos da Regra Teodosiana têm sido objeto da atenção dos mestres: o

45. Cód. 10, 31, 65, in fine: “... cum conveniat, leges fututis regulas imponere, non prasteritis CALUMNIAS EXCITARE"

46. Cód. I, XIV, 7. Do Codex Vetus, de 530, nada chegou até nós. V. SÍLVIO MEIRA, História e Fontes, p. 183. 
sentido da expressão - certum est: 47 o alcance da locução - pendentibus negotiis; 48 a contradição, que parece haver entre a sua primeira parte e a segunda; ${ }^{49}$ a inautenticidade das palavras — adhuc pendentibus negotiis; 50 a interpolação dos vocábulos — praeterito tempore 51 .

A sintese de quanto nos ocorreu a respeito destes diversos problemas que a Regra Teodosiana tem suscitado é a que vai adiante.

Primeiramente, ao que parece, a expressão certum est mostra que, de fato, o Princípio da Irretroatividade das Leis era já uma regra definitivamente radicada no espírito jurídico dos Romanos. Dir-se-á que poderia constituir simples referência à Primeira Regra Teodosiana; mas aí estão, para comprovar o contrário, a despeito da aridez e do primarismo jurídico da época anterior, as muitas regras não retroativas 52 ao mesmo passo que as retroativas revelam caráter excepcional.

Quanto ao alcance dos vocábulos - negotia pendentia, pensamos que efetivamente não se trata apenas dos atos jurídicos, senão dos fatos jurídicos em geral, isto é, dos facta pendentia. Com efeito, a idéia de que a retroprojeção da lei deve respeitar os facta de modo amplo e não apenas os negotia ou as causae já se encontra nos textos de UlPIANo e de Paulo, onde o neutro é utilizado através de adjetivos, sem o acompanhamento de substantivo algum que os possa restringir (judicata transacta finitave). Por outro lado, no próprio primeiro têrmo da Regra Teodosiana, cuja autenticidade jamais se pôs em dúvida, a expressão - futuris negotiis - é utilizada ao lado de - facta praeterita, com o mesmo valor e finalidade.

No que tange à contradição que se procurou ver entre a primeira (Princípio da Irretroatividade) e a segunda parte da regra (a retroatividade expressa como exceção), a nós nos parece que tal não existe. Como observa Contardo FERrini essa orientação foi sempre admitida em Ro-

47. ROUBIER, op. cit., I, p. 68; GAETANO PACE, op. cit., p. 37.

48. SAVIGNY, op. cit., VII, p. 393, nota b-7; ROUBIER, loc. cit., nota 1; GABBA, op. cit., I, p. 47.

49. REINAIDO PORCHAT, Da Retroatividade das Leis Civis, p. 77; TOMÁs MARKY, p. 267.

50. TOMAS MARKY, op. cit., p. 271.

51. MOMMSEN, apud SAVIGNY, loc. cit. p. 292, nota.

52. C. Th. 4, 12, 4; 12. 1, 19; 11, 18. Cf. TOMÁS MARKY, op. cit., p. 264-265. 
ma, bastando, para comprová-la a célebre controvérsia dos Veteres a respeito da Lex Atinia ${ }^{53}$. Com maior razão ainda, à face das peculiares características da monarquia absoluta 54

A possível interpolação das palavras praeterito tempore é irrelevante, pois admitir o respeito aos negotia pendentia já implica o tempus praeteritum, que, em matéria de retroatividade, significa menos.

Quanto à inautenticidade da referência pendentibus negotiis o ilustre Prof. Tomás MARKy apenas acenou com a sua possibilidade, sem, data venia, esmiuçar os respectivos fundamentos. Por outro lado, elementos há que nos levam a concluir pelo contrário, a saber: primeiro, dada a semelhança entre a regra de Teodósıo I e a primeira parte da Segunda Regra Teodosiana, uma vez que aquela consta de Codex, Teodósio II não teria tido a necessidade de promulgar uma novela sôbre o mesmo assunto, se não com a finalidade de abarcar matéria mais ampla; segundo, se Justiniano incluiu na sua compilação a Segunda Regra e não a Primeira, é porque esta atendia menos ao espírito da sua obra legislativa amplamente respeitadora dos facta pendentia.

O importante, porém, não já do ponto de vista histórico, mas segundo a perspectiva dogmático-jurídica, é que, a despeito das suas avançadas expressões, a Regra Teodosiana só vai alcançar a plenitude do seu significado, à face do sistema justinianeu, onde foi integrada à guisa de princípio fundamental.

1 Principais Textos. A matéria de Direito Intertemporal, na legislação justinianéia, se encontra principalmente do Código e nas Novelas. No Digesto, além dos textos de Ulpiano e de Paulo, já transcritos e comentados, parece ter certa importância o do Livro I, 4, 4, sobre a revogação das leis, onde se diz que - "as constituições posteriores no tempo tem mais força do que aquelas que as precederam" 55

53. CONTARDO FERRINI, op. cit., p. 40, eadem, nota 4.

54. SAVIGNY, op. cit., VIII, p. 393; “... questa constituzione ha il carattere di un'istituzione (cioè di una regola d'interpretazione) per il giudice, non per il legislatore".

55. Constitutiones tempore posteriores, potiores sunt his quae ipsas proecesserunt. D. 1, 4, 4, frag. de MODESTINO. 
São textos especialmente relevantes, além da Regra Teodosiana (C.1, 14, 7) os seguintes:

C. 1, 2, 22. 1 (em Hullot, 1, 2, 18, 1) Autênticas, n. ${ }^{0}$ 120, de JUSTINIANO.

Sobre as alienações $e$ as enfiteuses.

Quam oportet non solum in casibus, quos futurum tempus creaverit, sed etiam in adhuc pendentibus et judiciali termino, vel amicabili compositione necdum sopitis obtinere.

C. $1,17,2,23$ De Justiniano ao Senado e a todos os povos. (Cont. Tanta)

Promulgação das Institutas e do Digesto, datada de 17 das calendas de janeiro, de 533 .

Leges autem nostras, quae in his Codicibus, id est, Institutionum seu Elementorum, et Digestorum, vel Pandectarum posuimos 56, suum obtinere robur ex tertio nostro felicissimo sansimus consulatu praesentis duodecimae indictionis, tertio Kalendas Januarias, in omme aevum valituras, et una cum nostris constitutionibus pollentes: et suum vigorem in judiciis ostendentes ni omnibus causis, sive quae postea emerserint, sive quae in judiciis adhuc pendent, nec eas judicialis vel amicalis forma compescuit quae enim jam vel judiciali sententia finita sunt vel amicali pacto sopita, haec resuscitari nullo volumus modo.

C. 4, 20, $18{ }^{57}$ Autêntica, n. ${ }^{\circ}$ 90, de 528 .

Sobre a prova de pagamento mediante testemunhas.

his scilicet qui jam sine scriptis debitum vel partem ejus solverint, (a) praesenti sanctione merito excipiendis.

C. $4,32,26, \S 1 .^{\circ}$ Aut. de Justiniano

Sobre a usura excessiva.

56. Este é o texto de GALISSET; in HULLOT, há diferenças grandes de redação, mas não de substâncias.

57. Em SAVIGNY e GALISSET; em HULLOT, § 14. 
Si quis autem aliquid contra modum hujus fecerit constitutionis, nullam penitus de superfluo habeat actionem; sed et si acceperit, in sortem hoc imputare compelletur.

\section{4, 32, 27, Aut. de Justiniano}

Sobre a constituição anterior.

De usuris, quarum modum jam statuimus, pravam quarundam interpretationem penitus removentes, jubemus etiam eos, qui ante eadem. sanctionem ampliores quam statutae sunt, usuras stipulati sunt, ad modum eandem sanctione taxatum ex tempore lationis ejus suas moderari actionis; scilicet illius temporis quod ante eam defluxit legem, pro tenore stipulationis usuras exacturos.

C. 4, 29, 21. Do Imperador ANASTÁcio, ad SC Velleianum.

Sobre a validade da renúncia a direitos hipotecários da mulher.

omibus quae in praesenti per hanc consultissimam legem statuimus, ad praeteritos nihilominus contractus pro negotiis et controversiis, necdum transactionibus, vel definitivis sententiis, seu alio legitimo modo sopitis, locum habiluris.

C. $5,13,16$. De Justiniano, 530, textus codicis.

Sobre a ação de rei uxorie e ex stipulatu.

Quae omnia in his tantum modo dotibus locum habere censemus, quae post hanc legem datae fuerint, vel promissae, vel etiam sine scriptis habitae. Instrumenta enim jam confecta viribus carere non patimur, sed suum expectare eventum.

\section{C. $6,23,29$. Autêntica de Justiniano, 531}

Sobre os testamentos.

Quae in posterum tantummodo observari censemus; ut quae testamenta post hanc Novellam nostri nominis legem conficiuntur, haec cum observatione procedant. Quid enim antiquitas peccavit, quae praesenti legis inscia, pristinam secuta est observationem? 
C. 10, 31, 66. Do imp. Anastácio (em Hullot, § 65)

Sobre uma constituição de ZENON, a respeito dos bens dos decuriōes.

Eadem videlicet constitutione divae memoria Zenonis ex die, quo promulgata est, suas vires obtinente: cum conveniat, leges futuris regulas imponere, non praetieritis calumnias excitare.

Novela 19, prefácio.

Sobre as crianças nascidas antes do contrato dotal.

Nobis utique cum particulariter poneremus leges, expressim in prima constitutione quae hoc sancivit memorantibus, ut sive superaint eis paties, sive defuncti sint, nonlum tamen hujusmodi questiones aut sententiis aut transactionibus susceperunt terminum ... et in hanc quoque secundam nostram constitutionem similiter adjecimus, oportere ejus legislationem et ad seniora referri tempora, exceptis illi causis, quas aut judicialis sententia, aut transactio terminavit ... Sed quia in ipsa nostra constitutione non adjecimus aperte valere hujusmodi legislationem, etiam in illis quarum patres athuc supersunt aut defuncti quidem sunt, contentio autem neque judiciali sententia, neque amicabili interventione decisa est hin quidam arbitrari sunt nos nullatenus velle ea quae is memoratis continestur legislationibus de filiis qui ante celebrationem dotium nati sunt, valere etiam in illis qui ante hujusmodi legislationem nati sunt, et maxime eo, quod hujus pars in prima et secunda constitutione posita, ablata sit a nobis in Codicis compositione. Quod absurde arbitrati sunt. Justissime namque et primae et secundae hoc subtraximus constitutioni, et tertiae non adjecimus ... quatenus non multitudo superflua in Codice scriberetur. Tertia vero constitutione non adjecimus aliquil de temporibus, cum omnibus manifestum sit, oportere ea quae adjecta sunt, per interpretationem in illis valere in quibus interpretatis legibus sit locus.

Novela 22, 1, 1 De Nuptiis.

Sobre as segundas núpcias

Duo igitur haec praemittantur huic legi. Et primum illud; ut omnia quidem quaecunque in prioribus sancita sunt, sive a nobis, sive a prioribus nostris, haec valeant singula secundum propria tempora non haben- 
tia ullam ex praesenti lege novitatem; sed et in suis casibus valitura atque tractanda; et suos eventus ex iis quae jam positae sunt legibus expectantia et nihil communicantiis praesenti legi. etenim quod quidem omne jam praecessit conscriptis relinquimus legibus; quod vero futurum est, per praesentiem munimus legem. Illis enim credentes, et ita contrahentes, nullus culpabit quare non futurum sciverunt ..

\section{Cap. II}

Secundum vero illud; ut omnia quaecunque ex hodierna die testator disposuerit de talubus sive mulier consistat, haec valeant.

Novela $66,1,4 \quad U t$ factae novae constitutiones.

Sobre os testamentos.

Unde praeteritum omne justam habeat veniam, valeantque defunctorum voluntates et dispositiones, (vel si nuper factas sunt, sicut eas illi fecerunt Non enim infringi sicut praediximus) defunctorum volumus dispositiones; sed ratas esse per omnia declaramus; ut si vel proxime scripta sint testamenta post positionem legis, nondum vero contingerit, constitutiones factas innotuisse; et superviventibus forte testatoribus non sunt mutata; maneant etiam sic institutiones, quae ab initio secundum tunc certas extantes factae sunt leges, propriam virtutem habentes, et non acusandae eo quod tempore quo supervixerint illi; eas non mutaverunt. Non enim omnia sunt in nobis, nec semper quibusdam tempus fit testandi repente, plerumque enim incidunt hominibus mortes, testandi eis potestatem auferentes.

A despeito dos muitos outros textos, referentes à matéria, que se encontram no Código e nas Novelas, quer parecer-nos que estes são suficientes para evidenciar as linhas mestras no Direito Intertemporal em JusTINIANO.

2. Sintese do Direito Intertemporal Justinianeu. O lapso de quase um século que medeou entre o Código Teodosiano e a legislação justinianéia, a despeito da angústia a que se limitaram as fontes produtoras do Direito, deu azo a um gradativo amadurecimento do espírito jurídico dos 
Romanos. É certo que isso mal se nota nas constituições dessa época, exceção feita de algumas normas do imperador ANASTÁcıo. Mas a julgar pelo número de escolas jurídicas do tempo, e sobretudo pelo teor do trabalho de Triboniano e dos seus auxiliares ${ }^{58}$ aí se preparou o renascimento da Ciência do Jus Civile, de cuja definitiva influência o mundo civilizado se ressente até os nossos dias.

Não é pois de admirar que o Direito Intertemporal Justinianeu apresente uma riqueza sem precedentes.

O princípio fundamental que o domina é a Regra Teodosiana de 440, cujo teor é indispensável repetir: "É norma assentada a de que as leis e constituições dão forma aos negócios futuros e de que não atingem os fatos passados, a não ser que tenham feito referência expressa, quer ao passado, quer aos negócios pendentes"

Neste princípio vários preceitos se contêm, a saber:

I. A lei, de regra, regula tão somente o futuro e não o passado;

II. A lei, por isso que não se refere ao passado, não se aplica aos casos pendentes;

III. A lei, excepcionalmente, pode abranger o passado e os casos pendentes;

IV A lei só abrange o passado e os casos pendentes, quando inequivocamente expressa.

Ainda que não tenha havido interpolação na constituição de 440 é capital se note que, à face da sistemática do Corpus Juris Civilis, estas regras oferecem uma riqueza sem precedentes, quer no concernente à colaboração alheia, dos jurisconsultos compilados no Digesto, e dos imperadores do Código, quer no atinente à contribuição pessoal de Justiniano, tanto através das autênticas do Código, como das novelas subsequentes.

Assim, três idéias ficaram, de vez por todas, claramente definidas: a de facta futura, a de facta praeterita e a de facta pendentia.

Facta futura os sucedidos ex die legis.

58. JUSTINIANO, no De Confirmatione Digestorum, chama a aquele vir excelsus e aos demais viri magnifici et studiocissimi, ed. de MOMMSENKRUEGER, vol. I, p. 13, 16.a ed., Berlim, 1954. 
Facta praeterita os sucedidos ante diem legis.

Facta pendentia os sucedidos ante diem legis, mas cujos efeitos ultrapassam a promulgação da lei nova.

Quanto aos facta futura, o seu conceito não careceu de maior esmiuçamento, podendo-se dizer que o mesmo já estava implícito no próprio texto da tábua undécima da Lei das XII Tábuas.

Mas a noção de facta praeterita aparece em Justiniano pormenorizada pela contribuição dos Clássicos, abarcando os judicata, transacta finitave, conforme os fragmentos de Ulpiano e de PaUlo.

Nenhuma idéia, entretanto, foi tão enriquecida como a de facta pendentia, a qual, com efeito, é a que mais interessa ao desenvolvimento científico do Direito Intemporal.

Parece que não estamos errados em afirmar que, até então, o conceito de facta pendentia estava particularmente adstrito às causas controversiais pendentes de transação ou de decisão em juízo.

Mesmo admitindo-se que uma compreensão mais ampla já se esboçava anteriormente, conforme se poderia deduzir das próprias Verrinas de Cícero, o fato é que em Justiniano essa amplitude adquire linhas claras e inequívocas.

Na verdade, na Novela 22, a expressão - suos eventus - constitui uma referência explícita aos efeitos do ato jurídico que, não obstante se produzam no futuro, se devem regular ex iis quae jam positae sunt legibus. Na Autêntica 90 (C. 4, 20,18), pode dizer-se que se contém o respeito às estipulações de trato sucessivo, pois se deve reger conforme a lei antiga não só aquele que já pagou tơdo o seu débito, mas também o que simplesmente o já tenha feito em parte. E na Novela 66 é acatado o próprio testamento de pessoa que sobreviveu à lei nova e não teve tempo de modificá-lo.

Em vários lugares Justiniano, elucida o fundamento jurídico da não-retroprojeção das leis, a saber, a fides, a confiança no regime jurídico em vigor e a impossibilidade de se aplicarem normas ainda inexistentes 59 do mesmo modo que, através de uma constituição de ANASTácio

59. Novela 22, 1, 1; Novela 66, 1, 1; Código 6, 23, 29 in fine; CONTARDO FERRINI, p. 40. 
(C. 10, 31, 65), onde se encontra a locução - calumnias excitare realça, tal como o fizera TEodósio, o Grande, o caráter odioso e, por isso mesmo, restringendo, da retroatividade.

Assim, a retroatividade, além de excepcional, deve ser sempre expressa (Cód. 1, 14, 7; Novela 19, prefácio) e, mesmo em matéria de Direito Público a tendência é respeitar os facta finita (Constitutio tanta) ou fazê-la limitar-se ao efeito imediato (C. 4, 32, 27, De Usuris).

Por intermédio de um texto de Modestino ficou outrossim condenada a ultra-atividade da lei antiga (Digesto $1,4,4$ )

Finalmente, é relevante notar que Justiniano aplicou o Princípio da Irretroatividade das Leis a um grande número de matérias (testamentos, juros, dotes, estado de filiação, assuntos penais, etc.) e, sobretudo nas Novelas, emprestou ao tema um desenvolvimento sem precedentes em treze séculos de Direito Romano.

3. Significado e contribuição de Justiniano. Em quanto está contido nos dois parágrafos anteriores, especialmente no último, vai implícito o grande significado da contribuição de Justiniano para o progresso do Direito Intertemporal.

Como bem se pode aí aquinhoar, não se limitou o autor do Corpus Juris Civilis a mera obra de compilação, como, um século antes, fizera Teodósio II. Além da ordenação do direito antecedente, o que já de si fôra contribuição considerável, JUSTINIANo oferece criação própria, como bem se vê através das longas considerações sobre a matéria, insertas em várias de suas preclaríssimas Novelas.

Evidentemente, certa razão não deixa de assistir ao mestre REINALDo PoRChAT, ao afirmar, com referência ao Direito Romano, que "dos seus diversos dispositivos esparsos pelas coleções, fôra impossível deduzir sistematicamente uma doutrina completa e aceitável sobre a retroatividade" 60

O exame, porém, da evolução da matéria no Direito Antigo, e especialmente no Direito Romano, mostra quão grande foi o avanço dado por Justiniano, de tal forma que, se de um lado a sua doutrina não é com-

60. REINALDO PORCHAT. Da Retroatividade das Leis Civis p. 71. Revista de Direito Penal, n. 2, abr./jun., 1971. 
pleta, do outro, pedimos vênia para sustentar a existência de um esbôço de Sistema de Direito Intertemporal Justinianeu, de caráter pré-científico, inspiração e fundamento de quanto de mais desenvolvido, a partir daí, se produziu a respeito do assunto.

Muitas idades após, em pleno século XIX, a argúcia de suas lições ainda irá iluminar a cerebração dos mestres, e será com base nos textos do Codex e das Novelae que, com a Exegese e a Escola Histórica. se iniciará a Fase Centífica do Direito Intertemporal. 